\title{
Antibacterial Activity of Fresh Garlic Juice against Vibrio sp. Isolated from Shrimp Farm Water: An in vitro Study
}

\author{
A. Angela Mercy ${ }^{*}$ and A. Gopalakannan ${ }^{2}$ \\ ${ }^{1}$ Department of Fisheries Biotechnology, Institute of Fisheries post graduate Studies, \\ Chennai-603 103, Tamil Nadu, India \\ ${ }^{2}$ Department of Fish Health management, Fisheries College and Research Institute, \\ Ponneri-601 204, Tamil Nadu, India \\ *Corresponding author
}

\section{A B S T R A C T}

\section{Keywords}

Antibacterial, Vibrio sp., Shrimp

Article Info

Accepted:

07 April 2018

Available Online:

10 May 2018
Antibacterial activity of garlic was investigated on inhibition of Vibiro sp. isolated from shrimp farm water samples by well diffusion method. $100 \%$, $50 \%, 25 \%, 10 \%, 5 \%$ of Fresh garlic juices were prepared from $100 \mathrm{~g}$ garlic bulbs. Results indicated that the isolated Vibrio sp. showed different levels of sensitivity to different concentrations fresh garlic juice. The zone of inhibition of the bacterial growth increased with increasing concentration of fresh garlic juice. The results revealed that fresh garlic juice was effective against the test organism.

\section{Introduction}

Consumption of protein rich fish and fishery products has been dramatically increased all over the world. Among these, shrimps are in utmost demand as it is delicious and protein rich. In spite of reduced supply from capture side which is not up to the level to meet the increasing demand, aquaculture is focusing on the culture of shrimp in intensive manner. Intensification of production system has been followed by number of diseases. Whilst various forms of diseases have been reported in aquatic animals, most were caused by common bacteria (Morales, 2004; Holmstrom et al., 2003). To reduce the occurrence of diseases antimicrobial agents have been practiced in aquaculture. Unfortunately, excessive use of antibiotics led to the emergence of antibiotic-resistance among shrimp pathogens. This reduced the effectiveness of the prophylactic use of antibiotics in aquaculture (Sorum, 2000; Sorum, 2006). In addition to antibiotic resistance, presence of antibiotic residues has also been reported in shrimp and shellfish products (Wang et al., 2017; Cabello et al., 2013). This could eventually affect the beneficial microbes present in pond water and sediments, resulting in changes in microbial diversity in the shrimp pond (Hunter et al., 2005; Matyar et al., 2008). 
In this view, the development of effective and safe drug is necessary for shrimp health management. Natural products can be a valuable source for maintaining the health of the animal under culture. Garlic is reported to act as a strong antibacterial agent against various kinds of bacteria such as Escherichia coli, Shigella senteriae, Staphylococcus aureus, Salmonella sp., Streptococcus sp., Klebsiella sp., Proteus mirabilis, Pseudomonas aeruginosa and Helicobacter pylori (Indu et al., 2006).

The aim of this study is to detect the in vitro activity of Fresh Garlic Juice in the growth inhibition of Vibrio sp. isolated from shrimp farm water sample. Bacteria of the Vibrio genus are the causative agent for the majority of the diseases caused by bacteria in shrimp farm. If garlic shows some antimicrobial property against the disease causing Vibrio species, it could help to curb their growth in shrimp farm.

\section{Materials and Methods}

\section{Preparation of fresh garlic juice}

Fresh garlic was purchased from local market. Garlic was skinned and sliced; $100 \mathrm{~g}$ of sliced garlic pieces were crushed in sterile mortar and pestle and then the mixture was filtered through a sterile cloth. This filtrate was considered $100 \%$ fresh garlic extract was stored at $-20^{\circ} \mathrm{C}$, and was thawed before use. The $100 \%$ garlic juice (undiluted) was inoculated on nutrient agar media and incubated at $37^{\circ} \mathrm{C}$ overnight and was found to be sterile. The concentrated $(100 \%)$ juice was further diluted to $5 \%, 10 \%, 25 \%$ and $50 \%$ by mixing with distilled water.

\section{Culture medium}

Culture medium was prepared according to the producing companies instructions and after incubation at $37^{\circ} \mathrm{C}$ for 24 hours, used for culture of bacteria used in this study.

\section{Sample collection}

Shrimp farm water samples were collected from shrimp farms at Tiruvallur district, Tamil Nadu. $100 \mu \mathrm{l}$ of water sample was spread into TCBSagar plate with the help of a glass spreader. The plates were incubated at $37^{\circ} \mathrm{C}$ for overnight.

\section{Isolation of pure culture}

A nichrome inoculating loop was used to inoculate the isolated green colonies on TCBS agar. The inoculum was streaked into four quadrants of the nutrient agar plate with the help of an inoculation loop. The loop was sterilized between each successive quadrant streak. The purpose of this technique was to dilute the inoculum sufficiently on the surface of agar medium so that well-defined colonies of bacteria can be obtained.

\section{Preparation of bacterial culture}

All the bacterial isolates were picked up with the help of inoculating loop and were separately inoculated in a liquid media Tryptone Soy Broth (TSB) and incubated at $37^{\circ} \mathrm{C}$ for overnight. These bacterial cultures were further used for antibacterial assay.

\section{Well diffusion method screening}

Well diffusion technique was performed according to Saeed and Tariq, 2005. Three replicates Mueller Hinton Agar (MHA) was poured in petriplates of $9-10 \mathrm{~cm}$; depth of agar was 3-4 mm. A sterilised cotton swab was dipped into the suspension. The inoculum was then swabbed over the entire agar surface. The plate was allowed to dry for 3-5 min. Wells of $5 \mathrm{~mm}$ diameter were cut on the surface of the agar. Thirty microliter of $5 \%$, 
$10 \%, 25 \%, 50 \%$, and $100 \%$ solutions (v/v) of Fresh Garlic Juice was added to different wells and in one well, normal distilled water was added as a control. The plates were incubated at $37^{\circ} \mathrm{C}$ for $24 \mathrm{~h}$. The antibacterial activity was observed through zone of inhibition by measuring the diameter in millimeter $(\mathrm{mm})$ including disc diameter.

\section{Results and Discussion}

\section{Inhibitory effect of Fresh garlic juice}

To deal with the bacterial infections effective drugs need to be given attention. Unfortunately these effective drugs (antibiotics) has accompanied with unsafe indications, i.e. emergence of antibiotic resistance. This phenomenon of resistance has paved the way to safe and effective drugs for the treatment of bacterial infections. In this study garlic showed antibacterial activity against Vibrio sp. and the sensitivity was gradually increased with increasing concentration of fresh garlic juice. Inhibitory effect of garlic juice was tested against Vibrio sp. using agar well diffusion method where distilled water was used as a control. There was no zone of inhibition observed against distilled water. The inhibition zone was observed against garlic juice of different concentrations. The sensitivity of the bacteria against Fresh Garlic Juice gradually increased with the increase in concentration. The zone of inhibition at different concentrations of fresh garlic juice is presented in Figure 1 and Table 1. It was observed that five different concentrations of fresh garlic juice showed varied level of antibacterial activity against Vibrio sp.

Fig.1 Inhibitory effect of different concentrations of fresh garlic juice on growth of Vibrio sp.

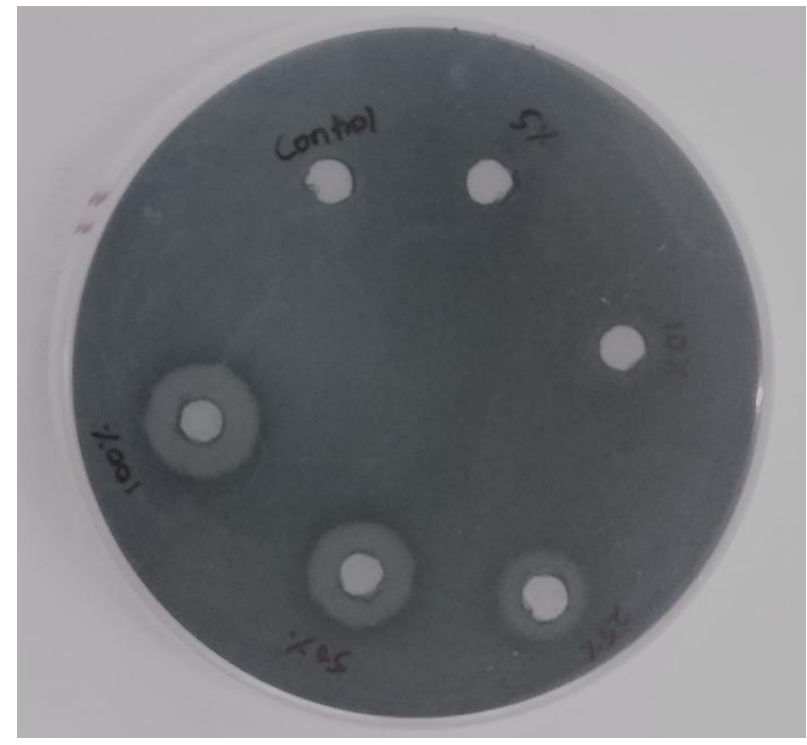

Table.1 Zone of inhibition at different concentration of fresh garlic juice against the growth of Vibrio sp.

\begin{tabular}{|l|c|c|c|c|c|}
\hline Conc. (\%) & 5 & 10 & 25 & 50 & 100 \\
\hline Zone of Inhibition (mm) & $6.5 \pm 0.03$ & $8.0 \pm 0.02$ & $12.0 \pm 0.05$ & $14.0 \pm 0.01$ & $16.0 \pm 0.02$ \\
\hline
\end{tabular}


Many reports have documented that garlic can effectively eliminate principal pathogenic bacteria including Pseudomonas sp., Edwardsiella sp. and Vibrio sp. Zhang (2003) has studied the inhibitory effects of garlic on two isolates of Aeromonas hydrophilla in vitro. It was shown to be effective with minimum inhibitory concentration of 15.6 $\mathrm{mg} / \mathrm{l}$ and $1.95 \mathrm{mg} / \mathrm{l}$ respectively for $\mathrm{AH} 1$ and AH2. Khashan (2014) has reported that garlic is effective against the growth of Staphylococcus aureus which is due to the allicin compound in the garlic extract. The sensitivity of the bacterium increased with increasing concentration of garlic. Yadhav et al., (2015) demonstrated an in vitro study to test the antibacterial effect of fresh garlic juice against five bacterial pathogens E. coli, Klebsiella pneumoniae, Proteus mirabilis, Pseudomonas aeruginosa, and Staphylococcus aureus. It was found to be effect against five bacterial pathogens. Since the use of antibiotics has been banned for use in aquaculture for disease inhibition in many developing countries effective therapeutic strategies need to be standardized. Drugs of herbal sources could serve as an effective measure to reduce the impact of diseases in aquaculture. It is apparent that fresh garlic juice could be a good antibacterial agent against Vibrio sp.

\section{Acknowledgements}

Authors acknowledge the Fisheries College \& Research Institute for providing support to carry out the research work.

\section{References}

Cabello, F.C., Godfrey, H.P., Tomova, A., Ivanova, L., Dolz, H., Millanao, A., and Buschmann, A.H. 2013. Antimicrobial use in aquaculture re-examined: its relevance to antimicrobial resistance and to animal and human health. Environtal Microbiology, 1917: 42.

Holmstrom, K., Graslund, S., Wahlstrom, A., Poungshompoo, S., Bengtsson, B. E., and Kautsky, N. 2003. Antibiotic use in shrimp farming and implications for environmental impacts and human health. International Journal of Food Science and Technology, 38: 255-266.

Hunter-Cevera, J., Karl, D., and Buckley, M. 2005. Marine microbial diversity: the key to earth's habitability. (A report from the American Academy of Microbiology) Collo-quium held 8-10 April 2005, San Francisco, CA, USA: Marine Microbial Diversity. Washington, DC, USA: American Academy of Microbiology.

Indu, M. N., Hatha, A.A.M., Abirosh, C. 2006. Antimicrobial activity of some of the south-Indian spices against serotypes of Escherichia coli, Salmonella, Listeria monocytogenes and Aeromonas hydrophila. Brazilian Journal of Microbiology, 37: 153-158.

Khashan. 2014. Antibacterial activity of garlic extract (Allium sativum) against Staphylococcus aureus in vitro. Global journal of bio-science and biotechnology. 3: 346-348.

Matyar, F., Kaya, A., and Dinçer, S. 2008. Antibacterial agents and heavy metal resistance in Gram-negative bacteria isolated from seawater, shrimp and sediment in Iskenderun Bay, Turkey. Science of the Total Environment, 407: 279-285.

Morales, C. M. S. (Ed). 2004. Enfermedades del camaron, Editorial Trillas, ISBN968-24-7112-5, Mexico, D. F.

Saeed, S., and Tariq, P. 2005. Antibacterial activities of Menthapiperita, Pisum sativum and Momordica charantia. Pakistan Journal of Botany, 37: 9971001 
Sorum, H. 2000. Farming of Atlantic salmon - an experience from Norway. Acta Veterinaria Scandinavica Supplementum, 93: 129-134.

Sorum, H. 2006. Antimicrobial Resistance in Bacteria of Animal Origin. Aarestrup, F.M. (ed.). Washington, DC, USA: American Society for Microbiology Press, p. 213-238.

Wang, H., Ren, L., Yu, X., Hu, J., Chen, Y., He, G., and Jiang, Q. 2017. Antibiotic residues in meat, milk and aquatic products in Shanghai and human exposure assessment. Food Control, 80:217-225.

Yadav, S., Trivedi, N.A., Bhatt, J.D. 2015. Antimicrobial activity of fresh garlic juice: An in vitro study. Аyu, 36(2): 203-207.

Zhang, L. 2003. Pharmacodynamics research of allicin on Aeromonas hydrophila. Water Conservancy Related Fisheries, 23:49-51.

\section{How to cite this article:}

Angela Mercy, A. and Gopalakannan, A. 2018. Antibacterial Activity of Fresh Garlic Juice against Vibrio sp. Isolated from Shrimp Farm Water: An in vitro Study. Int.J.Curr.Microbiol.App.Sci. 7(05): 485-489. doi: https://doi.org/10.20546/ijcmas.2018.705.060 